\title{
Neurotransmissor serotonérgico em relação a doenças psíquicas e seus fatores nutricionais: uma revisão sistemática
}

\author{
Serotonergic neurotransmitters in relation to mental illnesses and their nutritional factors: a \\ systematic review
}

Neurotransmissores serotoninérgicos em relación com lãs enfermedades mentales y sus factores nutricionales: uma revisión sistemática

\author{
Késya Salvino do Nascimento \\ ORCID: https://orcid.org/0000-0002-9169-7346 \\ Centro Universitário UNIFACISA, Brasil \\ E-mail: ns.kesya@gmail.com
}

\begin{abstract}
Resumo
A verificação do inquérito mediante a eficiência do neurotransmissor serotonina para com doenças neurológicas e transtornos concedeu-se resultâncias relevantes para a área de estudo do sistema nervoso, dado que a serotonina libera a sensação de bem-estar. Não obstante, a 5-hidroxitriptamina obteve relações com a parte nutricional de indivíduos com as doenças estudadas, assim, sucedeu-se um trabalho em conjunto para beneficiá-los. Objetivo: Investigar e compreender o neurotransmissor serotonina acerca dos problemas alimentares como melhoria para doenças e transtornos mentais. Metodologia: Trata-se de uma revisão sistemática com ambasamento na análise de 28 artigos dos anos de 2011 a 2020 em sites nacionais Scielo e BVS somado a livros da fisiologia, psicofarmacologia, anatomia e nutrição. Á vista disso, os resultados obtidos decorreu de que o sistema serotonérgico juntamente com a nutrição auxilia no tratamento da depressão, TEA, TDAH, SZC e DA. Conclusão: A serotonina atuando em soma com a alimentação mostra-se eficaz na melhora da saúde mental. Dessa forma, manter uma dieta conducente a saúde cerebral para a produção correta de serotonina é uma fator importante para o combate e prevenção.
\end{abstract}

Palavras-chave: Serotonina; Triptofano; Nutrição; Depressão; Transtornos mentais.

\begin{abstract}
Verification for the efficiency of the neurotransmitter serotonin for neurological diseases and disorders, has granted relevant in the study of the nervous system, given that serotonin releases the feeling of welfare state. However, 5hydroxtryptamine was related to the nutritional part of individuals with the diseases studied, thus, a joint work was carried out to benefit them. Objective: to investigate and understand the neurotransmitter serotonin in alimentary inssues as improviment for mental illness and disorders. Methodology: This is a systematic review based on the analysis of 28 articles from the years 2011 to 2020 on Scielo and BVS, plus books from the physiology, psychopharmacology, anatomy and nutrition. In view of this, the obtained results hás shwon that the serotonergic system together with nutrition issues helps in the treatment of depression, ASD, ADHD, SZC and AD. Conclusion: Serotonin acting on addition with food had shown to be effective in improving mental health. In this way, maintaining a diet conducive to brain health for the correct production of serotonin is an important factor for combat and prevention.
\end{abstract}

Keywords: Serotonin; Tryptophan; Nutrition; Depression; Mental disorders.

\section{Resumen}

La verificación de la indagación a través de la eficiencia del neurotransmisor serotonina por las enfermedades neurológicas y transtornos resultó relevante para el área de estudios del sistema nervioso, a ver que la serotonina libera la sensación de bienestar. Sin embargo, la 5- hidroxitriptamina obtuvo relaciones con la parte nutricional de individuos con enfermedades estudiadas, así siendo, se sucedió un trabajo conjunto para beneficiarlos. Objetivo: investigar y comprender el neurotransmisor serotonina sobre los problemas alimentares como una mejora a las enfermedades y desórdenes mentales. Metodología: consiste em una revisión sistemática con basada en en el análisis de 28 artículos de los ãnos de 2011 hasta 2020 en sitios nacionales, Scielo y BVS, agregados a libros de fisiología, psicofarmacología, anatomía y nutrición. En vista de eso, los resultados obtenidos resultaron que el sistema serotonérgico unido a la nutrición ayuda en el tratamiento de la depresióm, TEA, TDAH, SC y EA. Conclusión: la serotonina actuando juntamente a la alimentación demuestra eficacia para mejorar la salud mental. De esa forma, 
mantener una dieta propicia a la salud cerebral para la producción correcta de serotonina es un factor important para el combate y la prevención.

Palabras clave: Serotonina; Triptofano; Nutrición; Depresión; Transtornos mentales.

\section{Introdução}

O sistema serotonérgico é responsável pela evolução adequada do sistema neural. A serotonina, monoamina, diz respeito a uma parte fundamental no processo de elaboração da maturação do sistema nervoso central. Ao longo do desenvolvimento, desempenha o papel de agente sinalizador a nível celular, neuromodulador, hormônio e neurotransmissor. Conforme a elucidação, sua funcionalidade inclui questões de indução da neurogênese, diferenciação neurônica, sinaptogênese e consiste na autorregulação dos neurônios serotonérgicos e o progresso dos tecidos-alvos (Pinheiro et al., 2017).

A molécula como já supracitado, age como regulador do sono, ajuda na temperatura corporal, apetite, humor, atividade motora e nas partes cognitivas. A serotonina ou também conhecida como 5-hidroxitriptamina é produzida nos núcleos da rafe e difundida no órgão principal do sistema nervoso, o cérebro. Além disso, exerce a condução da comunicação de um neurônio para outro e é expelida pelas células nervosas serotonérgicas e atua em receptores de neurônios pós-sinápticos. Então, em concordância do que foi mencionado, as suas concentrações de 5-HT cerebrais relacionam-se a mudanças de conduta, ânimo, ansiedade, hostilidade, depressão, sono, fadiga, e remoção de apetência (Feijó et al., 2011). Esse neurotransmissor corresponde de modo hidrofílico e não transpassa a barreira hematoencefálica, devido a isso precisa-se ser sintetizado no cérebro a partir do aminoácido principal, o triptofano (Pinheiro et al., 2017).

O triptofano (TRP) é um aminoácido que encontra-se no plasma sanguíneo, o qual situa-se especialmente próximo à albumina, e com apenas uma pequena parcela no formato autônomo (Carvalho et al., 2017). Já que o próprio corpo não consegue sintetizar o TRP, para consegui-lo é exclusivamente através da dieta (Pinheiro et al., 2017). Ao cruzar a barreira hematoencefálica, seus metabólitos têm diferentes efeitos no neuroeixo. Portanto, há a existência significativa de metabólitos relevantes neuroativos subsequentes do metabolismo do triptofano, envolvendo a serotonina, melatonina, 3hidroxiquinurenina, ácido quinolínico e quinurênico e entre outros. Esses estão relacionados a doenças neurodegenerativas como a doença de Alzheimer e a de Huntington, e também as que correlacionam doenças neuropsiquiátricas como o transtorno bipolar (TB) e a esquizofrenia (SCZ). Outrossim, a depressão se faz presente nessa associação (Carvalho; et al, 2017).

Em torno de $90 \%$ do TRP absorvido é unido à albumina do plasma, e só 10\% é achado em formato livre no fluxo sanguíneo. O triptofano relaciona-se a um substrato para a criação de variadas moléculas neuroativas com ações biológicas, conforme a serotonina, a melatonina, a 3-hidroxiquinurenina, o ácido quinolínico, ácido quinurênico, etc. Existem duas vias primordiais no requisito de metabolização do TRP: 5-HT e quinurenina (QUIN). O triptofano (TRP) é um substrato para a síntese de 5-hidroxitriptamina (5-HT) no sistema nervoso central (SNC), também conhecido como 5-hidroxitriptamina (5-HT). A disponibilidade de TRP pode limitar a taxa de síntese de 5-HT. A ação da triptofano hidroxilase (TPH) hidrolisa o TRP em 5-hidroxitriptofano, que é rapidamente metabolizado em 5-HT. A serotonina é armazenada nas vesículas sinápticas dos neurônios serotonérgicos até que seja usada e / ou metabolizada em serotonina. A via QUIN do ácido indol acético (5-HIAA) é a via principal do metabolismo do TRP, é responsável por mais de $95 \%$ do metabolismo do TRP no corpo humano. O catabolismo de algumas enzimas importantes nessa via depende da presença de vitamina B2 e cofatores como a B6. Na dieta, em média 95\% do TRP refere-se à parte da metabolização pela via da QUIN, e cerca de 1\% do TRP converte-se em 5-HT no sistema nervoso central. Em contrapartida, o resto é conduzido à síntese de proteínas e de melanina para sofrer transformações nas vias metabólicas do triptofano. Na via da serotonina, o triptofano transforma-se em serotonina e melatonina, já na via da quinurenina, realiza-se a quinurenina e derivados como a nicotinamida adenina dinucleotídeo. A divisão do triptofano ingerido na alimentação auxilia como fonte para a síntese de melanina e bem como substrato para o processo de produção de novas proteínas (Carvalho; et al, 2017). 
A pesquisa tem como objetivo analisar e compreender os neurotransmissores serotoninérgicos em questões alimentares como benefício a doenças psíquicas e transtornos mentais, devido a liberação da serotonina ocorrer através do triptofano que encontra-se presente na alimentação. De forma analítica, a Nutrição pode apresentar possibilidades alimentares para a ocorrência da ativação serotonérgica.

\section{Metodologia}

Analisou-se artigos publicados no idioma inglês e em português tendo como referência as bases de dados Scielo, BVS, bem como, livros também contribuíram para essa análise. O estudo trata-se de uma revisão sistemática com abordagem qualitativa, pois visa reunir dados teóricos consistentes para melhor identificação de diagnósticos e tratamentos nas doenças psíquicas e transtornos mentais. Além do mais, refere-se a uma revisão focada em uma questão estabelecida, que propõe-se em identificar, analisar, selecionar e gerar as comprovações pertinentes para o estudo (Galvão \& Pereira, 2014). Sucederam artigos dos anos de 2011 a 2020 utilizando os seguintes descritores encontrados: Serotonin; Tryptophan; Nutrition; Depression e Mental Disorders. Os critérios de inclusão realizou-se por intermédio de 50 artigos, porém, foi aplicado os métodos de exclusão de 22 artigos, assim, trabalhou-se com 28 para a pesquisa.

\section{Procedimento das filtragens dos artigos}

Estabeleceu-se como critérios de inclusão os artigos científicos que estivesse de acordo com a temática, já os critérios de exclusão sucedeu a duplicação de estudos e conteúdo de pouca relevância a pesquisa. Ademais, a Figura 1 demonstra como o procedimento foi realizado e a Tabela 1 apresenta os artigos finais que foram selecionados.

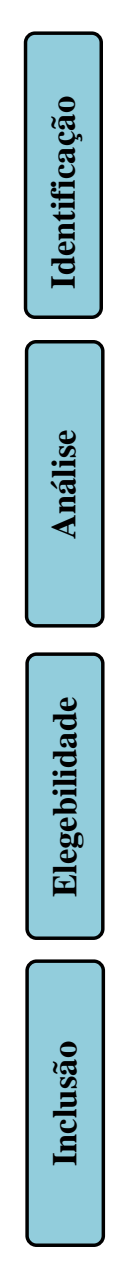

Figura 1. Descrição das filtragens dos artigos selecionados.

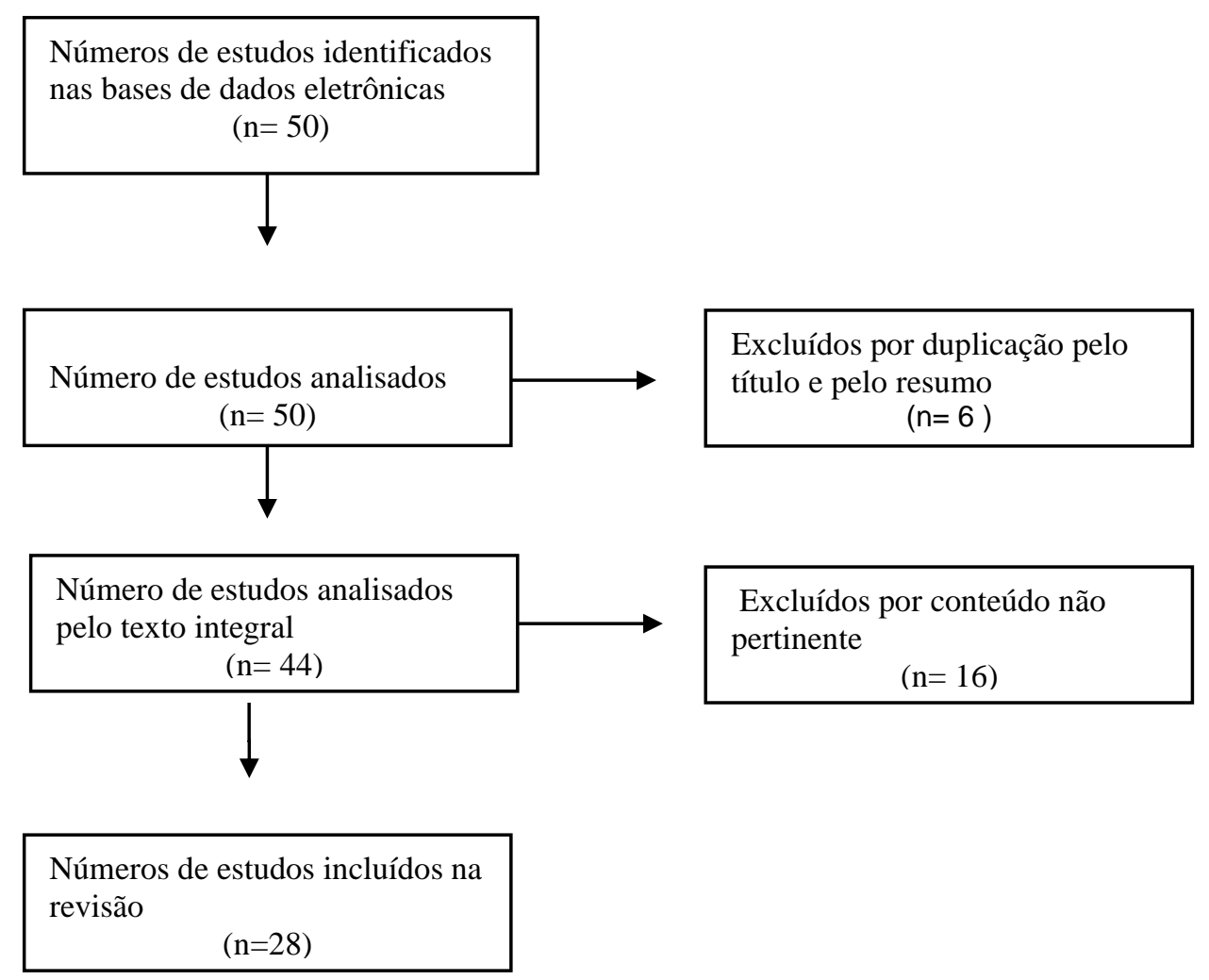

Fonte: Dados da pesquisa. 
Tabela 1. Artigos selecionados para a pesquisa.

\begin{tabular}{|c|c|c|c|}
\hline Autor/título & Palavras chaves & Tipo & Ano \\
\hline $\begin{array}{c}\text { Bonan, C., Texeira, L.A. \& Nakano, A.R. Absorção e } \\
\text { metabolização dos hormônios sexuais e sua transformação em } \\
\text { tecnologias contraceptivas: percursos do pensamento médico no } \\
\text { Brasil. }\end{array}$ & $\begin{array}{l}\text { Hormônios sexuais; Contracpeção; } \\
\text { Pensamento médico; Revista médica; } \\
\text { História. }\end{array}$ & Artigo & 2017 \\
\hline $\begin{array}{l}\text { Câmera, A.B. Receptores neurais e a doença de Alzheimer: uma } \\
\text { revisão sistemática da literatura sobre as famílias de receptores } \\
\text { mais associadas a doença, suas funções e áreas de expressão. }\end{array}$ & $\begin{array}{l}\text { Receptores neurais; Doença de Alzheimer; } \\
\text { Proteína beta amiloide. }\end{array}$ & Artigo & 2019 \\
\hline $\begin{array}{c}\text { Carvalho, M.S., Mas, C.D., Nunes, D.F.S., Yonamine, C.M., \& } \\
\text { Hayashi, M.A.F. Metabolismo do triptofano em transtornos } \\
\text { mentais:Um enfoque na esquizofrenia. }\end{array}$ & $\begin{array}{l}\text { Triptofano; Quinurenina; Doenças } \\
\text { psiquiátricas; esquizofrenia. }\end{array}$ & Artigo & 2017 \\
\hline $\begin{array}{c}\text { Cardoso, F.L.E., Santos, L.C.M., Tenório, A.P.O., Lopes, M.R., \& } \\
\text { Barbosa, R.H.A. Suplementação de vitamina D e seus análogos } \\
\text { para tratamento de disfunção endotelial e doenças } \\
\text { cardiovasculares. }\end{array}$ & $\begin{array}{l}\text { Vitamina D; Doenças cardiovasculares; } \\
\text { endotélio; Suplementos nutricionais. }\end{array}$ & Artigo & 2020 \\
\hline $\begin{array}{l}\text { Cotrim, J.R., Lemos, A.G., Júnior, J.E.N., \& Barela, J.A. } \\
\text { Desenvolvimento de habilidades motoras fundamentais em } \\
\text { crianças com diferentes contextos escolares. }\end{array}$ & $\begin{array}{l}\text { Educação física; Ensino fundamental e } \\
\text { médio; Desenvovilmento humano. }\end{array}$ & Artigo & 2012 \\
\hline $\begin{array}{l}\text { Chaves, L.G.S., Gama, D.R.N., Castro, J.B.P., Oliveira, K.R.S.G., } \\
\text { \& Vale, R.G.S. Cortisol and serotonin levels in schizophrenic } \\
\text { inpatients undergoing aerobic training. }\end{array}$ & $\begin{array}{l}\text { Aerobic exercise; Hormone; Schizophrenia; } \\
\text { Cardiorespiratory fitness; Exercise therapy. }\end{array}$ & Artigo & 2020 \\
\hline $\begin{array}{l}\text { Fábregas, B.C., Vitorino, F.D., \& Texeira, A.L. Deficiência de } \\
\text { vitamina B12 e transtorno depressivo refratário. }\end{array}$ & $\begin{array}{l}\text { Depressão; vitamina B12; tratamento; } \\
\text { refratariedade. }\end{array}$ & Artigo & 2011 \\
\hline $\begin{array}{l}\text { Falco, A., Cukierman, D.S., Davis, R.A.H., \& Rey, N.A. Doença } \\
\text { de Alzheimer:Hipóteses etiológicas e perspectivas de tratamento. }\end{array}$ & $\begin{array}{c}\text { Alzheimer's disease; } \beta \text {-amyloid; Metal } \\
\text { Homeostasis; Acetylcholine; Glutamate; } \\
\text { diabetes }\end{array}$ & Artigo & 2016 \\
\hline $\begin{array}{l}\text { Ferreira, C.V., Góis, R.S., Gomes, L.P., Britto, A., Afrânio, B., \& } \\
\text { Dantas, E.H.M. Nascidos para correr: A importância do exercício } \\
\text { para a saúde do cérebro. }\end{array}$ & Exercício; Neurociência; Saúde mental & Artigo & 2017 \\
\hline $\begin{array}{l}\text { Feijó, F.M., Bertoluci, M.C., \& Reis, C. Serotonina e controle } \\
\text { hipotalâmico da fome: uma revisão. }\end{array}$ & $\begin{array}{c}\text { Serotonina; Receptor 5-HT2C de Serotonina; } \\
\text { Regulação do apetite; Resposta de saciedade; } \\
\text { Hipotálamo. }\end{array}$ & Artigo & 2011 \\
\hline $\begin{array}{l}\text { Flora, R.P.D., Dionello, N.J.L., Benitez, L., Germano, J.M., } \\
\text { Gotuzzo, A.G., \& Freitas, S. Expressão gênica de IGF-I e GHR no } \\
\text { fígado e no músculo do peito de codornas de corte suplementadas } \\
\text { com diferentes níveis de metionina em duas gerações sucessivas. }\end{array}$ & Crescimento; Extração de RNA; Geração. & Artigo & 2017 \\
\hline $\begin{array}{l}\text { Maia, C.S., Menezes, K.M.C., Tenorio, F.C.A.M., Júnior, } \\
\text { J.R.A.Q., \& Maciel, G.E.S. Transtorno do espectro autista e a } \\
\text { suplementação por ácido fólico antes e durante a gestação. }\end{array}$ & $\begin{array}{l}\text { Transtorno do espectro autista; Suplementos } \\
\text { pré-natais; Ácido fólico; Embriogênese; } \\
\text { desenvolvimento mental. }\end{array}$ & Artigo & 2019 \\
\hline $\begin{array}{l}\text { Machado, I.E., Malta, D.C., Bacal, N.S., \& Rosenfeld, L.G.M. } \\
\text { Prevalência de anemia em adultos e idosos brasileiros. }\end{array}$ & $\begin{array}{l}\text { Anemia; Anemias nutricionais; Fatores de } \\
\text { risco; Adulto; Idoso. }\end{array}$ & Artigo & 2019 \\
\hline $\begin{array}{c}\text { Martins, J.T., Silva, M.C., \& Streck, E.L. Efeitos da vitamina B12 } \\
\text { no cérebro. }\end{array}$ & $\begin{array}{c}\text { Vitamina B12; Doenças Neurológicas; } \\
\text { Cérebro; Cognição } \\
\end{array}$ & Artigo & 2017 \\
\hline $\begin{array}{c}\text { Neto, L.M.L., Vasconcelos, F.M.N., Silva, J.E., Pinto, T.C.C., } \\
\text { Sougey, E.B., \& Ximenes, R.C.C. Diferenças nas concentrações de } \\
\text { cortisol em adolescentes com transtornos alimentares: uma análise } \\
\text { sistemática. }\end{array}$ & $\begin{array}{l}\text { Cortisol; Transtornos alimentares; Anorexia; } \\
\text { Anorexia nervosa; Adolescente. }\end{array}$ & Artigo & 2019 \\
\hline $\begin{array}{c}\text { Neto, S.G.B., Brunoni, D., \& Cysneiros, R.M. Abordagem } \\
\text { psicofarmacológica no transtorno do espectro autista: uma revisão } \\
\text { narrativa. }\end{array}$ & $\begin{array}{l}\text { Transtorno autístico; Psicotrópicos; } \\
\text { Psicofarmacologia; Farmacoterapia; } \\
\text { Assistência farmacêutica. }\end{array}$ & Artigo & 2019 \\
\hline $\begin{array}{c}\text { Pinheiro, I.L., Santana, B.J.R.C., Galindo, L.C.M., Castro, R.M., \& } \\
\text { Sousa, S.L. Perinatal serotonergic activity: A decisive factor in the } \\
\text { control of food intake. }\end{array}$ & $\begin{array}{l}\text { Eating; Malnutrition; Serotonin; Serotonin } \\
\text { uptake inhibitors. }\end{array}$ & Artigo & 2017 \\
\hline $\begin{array}{l}\text { Santos, E.C., Brito, A., \& Pereira, I.R.O. Deficiência da vitamina } \\
\text { B12: um fator que induz a depressão?. }\end{array}$ & $\begin{array}{l}\text { Depressão; Deficiência de vitamina B12; } \\
\text { Homocisteína; S-adenosilmetionina. }\end{array}$ & Artigo & 2016 \\
\hline $\begin{array}{c}\text { Sauressig, C., Silva, V.L., Antunes, L.C., \& Dall’alba, V. Níveis de } \\
\text { Zinco sérico em pacientes internados com depressão }\end{array}$ & Zinco; Depressão. & Artigo & 2016 \\
\hline $\begin{array}{c}\text { Garcia, L.R.S., Silva, J.D.M., Silva, C.S.S., Rocha, P.J.S., \& } \\
\text { Garcia, L.C.S. Aspectos nutricionais no transtorno de } \\
\text { atenção/hiperatividade em crianças. }\end{array}$ & $\begin{array}{l}\text { Transtorno do Déficit de Atenção e } \\
\text { Hiperatividade, Dieta, Nutrição. }\end{array}$ & Artigo & 2017 \\
\hline
\end{tabular}




\begin{tabular}{c|c|c|c}
\hline $\begin{array}{c}\text { Siqueira, K.B., Binoti, M.L., Nunes, R.M., Borges, C.A.V., Pilati, } \\
\begin{array}{c}\text { A.F., Marcelino, G.W., Gama, M.A.S., \& Silva, P.H.F. Custo } \\
\text { benefício dos nutrientes dos alimentos consumidos no Brasil. }\end{array}\end{array}$ & $\begin{array}{c}\text { Nutrição; Saúde pública; Deficiência } \\
\text { nutricional; Custos. }\end{array}$ & Artigo & 2020 \\
\hline $\begin{array}{c}\text { Tuleski, S.C. A unidade do Psiquismo Humano para Vigotski e a } \\
\text { Desagregação desta na Esquizofrenia. }\end{array}$ & $\begin{array}{c}\text { Esquizofrenia; Vigotski; Psicologia } \\
\text { Histórico-Cultural; Formação de conceitos. }\end{array}$ & Artigo & 2019 \\
\hline
\end{tabular}

Fonte: Elaborado pelos autores.

Dos 50 artigos estudados, 22 não apresentaram os critérios de inclusão solicitados para a análise de estudo. A aplicação do critério de inclusão sucedeu em 28 artigos totalizando $56 \%$ dos artigos analisados para a respectiva pesquisa, bem como, os artigos selecionados foram resumidamente separados em autor/título, palavras chaves, tipo e ano.

\section{Resultados e Discussão}

Os neurotransmissores são mensageiros químicos produzidos pelo neurônio pré-sináptico e mantêm-se arquivados em vesículas sinápticas, pois as sinapses caracterizam o elemento central funcional do sistema nervoso e são ditas como uma área de encontro entre um neurônio pré-sináptico com um neurônio pós-sináptico. Na sinapse química, o neurônio pré-sináptico disponibiliza o neurotransmissor que liga-se ao seu receptor efetivo na membrana do terminal pós-sináptico. Esse fenômeno estimula uma reação elétrica, encaminhando à uma excitação ou inibição do neurônio pós-sináptico (Sthal, 2019). Em decorrência do exposto, no que diz respeito ao desempenho funcional da serotonina, os neuromoduladores são substâncias liberadas pelos neurônios que induzem a chance de uma inversão do potencial ser gerado na célula pós-sináptica, por exemplo, um neuromodulador que de forma reduzida faz a liberação de um neurotransmissor excitatório de um terminal pré-sináptico que reduz a probabilidade da elaboração de uma potencialidade de ação na célula pós-sináptica (Vanputte; Regan \& Russo, 2016). Já os hormônios são as mais diversas substâncias químicas, secretadas em diferentes órgãos e possuem diferentes gradientes de receptores em todo o organismo (Bonan et al., 2016).

A serotonina possui como propósito o ato de inibir a condução e tem uma meta de ajuste generalizado para a atividade mental. Sendo assim, afeta quase todas as funcionalidades do cérebro, impossibilita ou incentiva o ácido gama-aminobutírico (Feijó et al., 2011). O gama funciona como um transmissor inibitório (Guyton \& Hall, 2017). Esmera-se a coordenação motora como caracterização pela eventualidade de variações qualitativas e quantitativas no repertório motor ao longo da vida (Cotrim et al., 2011). Em relação à atividade motora, pesquisas já realizadas evidenciou-se que o exercício agudo modula a maior parte dos neurotransmissores no SNC ligados à suspensão e sedação (GABA), condição de atenção (norepinefrina), circuito de informação (dopamina) e ânimo (serotonina) (Ferreira et al., 2017).

A norepinefrina é segregada por terminais de numerosos neurônios, dos quais corpos celulares situam-se no tronco cerebral e no hipotálamo. De modo específico, os neurônios secretores de norepinefrina, encontrados no locus ceruleus fixo na ponte, lançam fibras nervosas para regiões encefálicas bastante dispersas do encéfalo, contribuindo no domínio do desempenho generalizado e na disposição mental. De forma constante, a norepinefrina em múltiplas dessas zonas, possivelmente envolve a ligação de receptores excitatórios, porém, contrariamente, em pequenos territórios vincula-se a receptores inibitivos. A dopamina é secretada por neurônios que resultam-se na substância negra. Em seguida, tais neurônios se incidem especialmente para a maior região dos gânglios da base, o estriado. O intuito da dopamina é geralmente de inibição. A serotonina trabalha como um inibidor das vias da dor na medula espinal, e menciona-se que seu feito inibitório nos espaços eminentes do sistema nervoso ajude no comando do estado de espírito do sujeito e eventualmente incluindo a provocação do adormecimento. (Gyuton \& Hall, 2017). O estímulo das monoaminas pela movimentação física amplia as possibilidades de melhoria dos transtornos mentais como depressão, ansiedade e estresse. Fatores neuroquímicos liberados no decurso da prática do exercício agudo envolvem o acréscimo na síntese de opióides e endocanabinóides. Esses, são conscienciosos pela sensação de entusiasmo, bem-estar, sedação e diminuição da sensibilidade e da dor. O procedimento de biossíntese da serotonina pode-se 
conseguir pelo desenvolvimento de seu precursor triptofano no cérebro, motivado pelo exercício. A serotonina é capaz de formar memórias relativas ao medo e reduzir os reflexos das respostas de episódios ameaçadores por intermédio de arremessos serotoninérgicos que iniciam-se do núcleo da rafe para o hipocampo (Ferreira et al., 2017).

\subsection{Depressão e B12}

Ademais, a falta de algumas vitaminas e minerais contribuem para o surgimento de doenças psíquicas. A vitamina B12, por exemplo, faz-se de suma importância, pois é um micronutriente essencial e efetua diversas finalidades em vias metabólicas obrigatórias para o sistema nervoso central e sistema periférico (Martins et al., 2017). A deficiência da B12, provoca um estado de hiperhomocisteinemia e a redução de S- adenosilmetionina (Santos et al., 2016).

A S-adenosilmetionina (SAM) é um composto que dispõe de uma responsabilidade pelas metilações elementares para a biossíntese de uma diversidade de componentes que fazem parte dos quesitos celulares, como creatina, carnitina, fosfolipídeos e proteínas (Flora et al., 2017).

Por essa razão torna-se um risco para a depressão. Uma das primeiras concepções neurobiológicas sobre depressão chegou-se em uma pressuposição da carência de monoaminas ou aminas biogênicas, que abrangem uma parte alifática - amina - e uma parte aromática - catecol ou indol. Os radicais livres catecol elaboram catecolaminas nomeadas norepinefrina (NE), epinefrina e dopamina (DA). O radical livre indol ocasiona indolaminas como a serotonina e a histamina. O sistema monoaminérgico localiza-se nos pequenos núcleos do tronco encefálico e mesencéfalo, e se expande por meio do córtex e do sistema límbico (cérebro emocional). A noradrenalina, a serotonina e a dopamina são capazes de atuar como reguladores na atividade psicomotora, o apetite, o sono e o humor (Santos et al., 2016).

Com ênfase ao neurotransmissor 5-HT, as modificações nos níveis de 5-HT, ou seja, os baixos níveis ou dificuldades na sinalização com o receptor apresentam relações de interesse na ingestão de doces e glicídios. Em uma certa quantia considerada comum de serotonina, o sujeito alcança com facilidade o estado pleno de satisfação do apetite e obtém melhor domínio a respeito da deglutição de açúcares. O nível apropriado do 5-HT na parte cerebral resulta quando ingere-se dieteticamente o triptofano, aminoácido precursor da serotonina e sacarídeos. Aproximadamente em 35 anos de estudos científicos indicam que essa molécula biológica exerce um significativo papel na questão da saciação. Destarte, a 5hidroxitriptamina apodera-se como um centro provável para a administração do peso. Substâncias que interditam a reabsorção de 5-HT são frequentemente utilizadas para o emagrecimento, tornando-se muito aplicado na abordagem do tratamento da obesidade, visto que, impulsionam a capacidade de saciar-se nos segmentos de pós-ingestão e pós-absorção nas partes alimentares (Feijó et al., 2011).

O pressuposto de que os neurotransmissores são diminuídos na fenda sináptica em áreas específicas do cérebro acarreta à depressão. Essa doença pode ser associada tanto com modificação da abundância de neurotransmissores, quanto com o número e a sensibilidade dos neuroreceptores (Santos et al., 2016). A Figura 2 demonstra-se a parte preventiva a depressão e suas relações vitamínicas.

De forma sugerida nos conhecimentos estudados, quando há a carência dessas vitaminas, em parte é possível esclarecer fisiopatologicamente as alterações de humor (serotonina, norepinefrina e dopamina) devido à metilação de moléculas precursoras da monoamina (Fábregas et al., 2011). 
Figura 2 - Determinou-se que alguns nutrientes são importantes para prevenir o desenvolvimento de sintomas depressivos.

\begin{tabular}{|l|l|}
\hline \multicolumn{1}{|c|}{$\begin{array}{c}\text { Nutriente ou } \\
\text { substância quimica }\end{array}$} & \multicolumn{1}{c}{\begin{tabular}{c}
\multicolumn{1}{c}{ Papel relacionado à prevenção } \\
de morbidade depressiva
\end{tabular}} \\
\hline $\begin{array}{l}\text { Ácidos graxos do } \\
\text { tipo n-3 } \\
\text { (Hibbeln, 1998; Lu } \\
\text { et al., 2010; Chalon } \\
\text { et al., 2001; Delion } \\
\text { et al., 1994) }\end{array}$ & $\begin{array}{l}\text { Nos tecidos cerebrais, os ácidos graxos n-3 parecem interferir no meta- } \\
\text { bolismo e na sinalização da serotonina, neurotransmissor fortemente as- } \\
\text { sociado ao humor. Além disso, os n-3 reduzem o estado inflamatório da } \\
\text { micrólia (sistema imunológico associado ao sistema nervoso central). A } \\
\text { composição das membranas dos neurônios, quando elevada em n-3, au- } \\
\text { menta a fluidez dos transportes intercelulares, facilitando as sinapses. }\end{array}$ \\
$\begin{array}{l}\text { Vitaminas e mine- } \\
\text { rais antioxidantes } \\
\text { (Gómez-Pinilla, 2008) }\end{array}$ & $\begin{array}{l}\text { Antioxidantes säo capazes de minimizar as consequências de um esta- } \\
\text { do inflamatório crônico, muito comum em morbidades depressivas. }\end{array}$ \\
\hline $\begin{array}{l}\text { Ácido fólico, } \\
\text { vitamina B6 e } \\
\text { vitamina B12 } \\
\text { (Araujo et al., 2015) }\end{array}$ & $\begin{array}{l}\text { Esse conjunto de vitaminas tem participação no chamado "metabolismo } \\
\text { de um carbono". Essa via metabólica permite a formação de precurso- } \\
\text { res de neurotransmissores, fosfolipides e mielina. Outro intermediário } \\
\text { importante nessa via é a homocisteina. A reduçäo dessas três vitaminas } \\
\text { permite a maior produção de Hys, que tem ações neurotóxicas. }\end{array}$ \\
\hline $\begin{array}{l}\text { Flavonoides } \\
\text { (Gomez-Pinilla, 2008) }\end{array}$ & $\begin{array}{l}\text { Além da função antioxidante, alguns flavonoides parecem atuar direta- } \\
\text { mente nas vias de produção de citocinas inflamatórias. Além disso, são } \\
\text { capazes de contribuir com a indução da neurogênese. }\end{array}$ \\
\hline \hline $\begin{array}{l}\text { Fibras alimentares } \\
\text { (Geurts et al., 2014) }\end{array}$ & $\begin{array}{l}\text { A relação entre ingestão de fibras e inflamação ocorre pela melhora da } \\
\text { microbiota intestinal, com consequente ação sobre a inflamação crôni- } \\
\text { ca. Melhorando a inflamação crônica, a neuroinflamação também é re- } \\
\text { duzida, proporcionando beneficios em sintomas depressivos. }\end{array}$ \\
\hline
\end{tabular}

Fonte: Aquino e Philippi (2017).

Princípios genéticos, fisiológicos, bioquímicos, morfológicos e ambientais vinculam-se ao aparecimento de doenças. A depressão é designada pela infelicidade ou irritabilidade, falta de prazer e energia, ausência de autoestima, frustração, pessimismo, arrependimento, diminuição de concentração, morte, perspectivas em relação ao suicídio, mudanças no sono e apetite. Assim, a classe de recaptação de inibidores de serotonina é utilizada para o tratamento (Saueressig et al., 2016).

Em conformidade do que foi referido relacionado à nutrição, a falta dos minerais, zinco e ferro, segundo os estudos, atinge ainda mais indivíduos com TDAH (Transtorno do Déficit de Atenção e Hiperatividade), pois há possibilidades nutricionais serem inadequadas desde a infância, e isso pode afetar a capacidade cognitiva, mais especificamente, a função executiva do cérebro. O transtorno é designado por desconcentração, ansiedade, atitudes impulsivas e exagero de ações motoras. Além do mais, na faixa etária infantil apresentam problemas a níveis emocionais. Etiologicamente, na bioquímica do TDAH é possível afirmar de forma conexa os baixos níveis ou subutilização de catecolaminas (epinefrina, norepinefrina, dopamina e de serotonina em algumas áreas cerebrais). Os neurotransmissores citados são encarregados pela ativação nas áreas do cérebro do lobo frontal, crucial para a realização do foco e atenção, visto que, uma vez com o acometimento nesta região, que geralmente dispõem sinais inibitórios para as outras divisões do cérebro, faz as partes responsáveis pela concentração ficarem ativas e são elaboradas falhas no controle inibitório, com isso, irá suscitar estímulos excitatórios em exorbitância que consequentemente afeta na desatenção. O zinco é uma parte importante para o organismo e é essencial para o crescimento, função imunológica e evolução do sistema nervoso. Também é um cofator importante para o metabolismo dos neurotransmissores, na conversão de B6 em sua figura ativa existindo a necessidade da conversão do triptofano em serotonina e por isso, melhora o estado de pessoas com TDAH. A vitamina B6 refere-se a algumas fontes alimentares (frango e vísceras, leguminosas, batatas, banana e aveia) da piridoxina, que é necessária para a conversão metabólica do triptofano em niacina, 
além de promover a liberação de glicogênio do fígado e dos músculos, pois participa da síntese da hemoglobina e da produção da mielina, regulando a síntese de um neurotransmissor fundamental no funcionamento cerebral (Carelle \& Cândido, 2014).

O mineral zinco é primordial no desempenho das organizações estruturais cerebrais e neurais, em que a concentração mais alta encontra-se no hipocampo e locais da amígdala do órgão central nervoso, usado para articular a transferência sináptica e agir como um neuromodulador endógeno de receptores cruciais como o AMPA, NMDA e GABA. Ainda mais, através de suas aplicações catalíticas, estruturais e regulatórias, efetua um papel relevante no processo de defesa do corpo pelo sistema imunológico e no estresse oxidativo ao precaver a geração de radicais livres e preservar estruturas biológicas. O ferro institui-se a síntese de hemoglobina e desenvolve um papel significativo na parte estrutural e operacional do sistema nervoso central, assim, é substancial para a neurotransmissão. Encarrega-se de execuções principais nas funções neurológicas, como a biossíntese e degradação da dopamina. Os indícios da falta do mineral ferro conseguem acrescentar a atenuação da concentração, o impasse em despertar e a aptidão de resposta. Na etiologia do transtorno, a desnutrição é considerada uma interferência devido à eliminação de números celulares e modificação no estado neuroquímico cerebral (Siqueira et al., 2017).

Um dos problemas mais rotineiros da sociedade global na hodiernidade é a lacuna nutricional. Essa falta de nutrientes de compostos orgânicos e inorgânicos deteriora a evolução intelectiva, cognitiva e física, como também ocasiona doenças e mortes prematuras, o que impede um terço do mundo a sobreviver em estados físicos e psíquicos inferior em nível bom (Siqueira et al., 2020). Considerando o importante papel do ferro no organismo desde a gestação até a fase idosa, a carência de tal mineral é preponderante para episódios anêmicos. A anemia é estabelecida como a perda da apuração de números das células vermelhas na linfa ou no seu potencial de carregar oxigênio pela hemoglobina para suprir às primordialidades física, orgânica, mecânica e bioquímica (Machado et al., 2019).

\subsubsection{Transtorno do Espectro do autismo e B9}

Em seguida, o Transtorno do Espectro do autismo (TEA) é caracterizado como um distúrbio do neurodesenvolvimento, definido por déficits sociais e comportamentais. As intervenções são farmacoterapêuticas para testar o estabelecimento do domínio dos sintomas acessórios que constituem o quadro. A serotonina avalia-se como um coadjutor para os comportamentos recorrentes e para a ansiedade (Neto et al., 2019). Pode-se distinguir as alterações genéticas capazes de causar o avanço do TEA nas crianças. Contudo, os testes moleculares podem indicar somente $25 \%$ das variações que acarretam o distúrbio. As ocorrências no decorrer da gestação, como a deglutição de algumas substâncias medicamentosas, ingestão de nutrientes e exposição a agentes tóxicos são fatores para ocasionar o aparecimento desse transtorno. A ingestão da alimentação pela mãe ao longo dos 9 meses torna-se imprescindível para a gênese normal do embrião. Dessa forma, um micronutriente relevante é o ácido fólico, conquistado através do alimento, por exemplo, em folhas verdes, fígado e frutas cítricas. Na embriogênese, a B9 é de extrema influência no progresso do tubo neural, estrutura precursora do sistema nervoso central. Segundo a Organização Mundial de Saúde, a porção de ácido fólico sugerida, antes ou durante a gravidez, é de 0,4 mg (= 400 $\mu \mathrm{g})$ uma vez ao dia. Isso irá prevenir possíveis erros do tubo neural (Maia et al., 2019).

\subsubsection{Esquizofrenia e níveis altos de cortisol}

A esquizofrenia (SCZ) atinge mais de 51 milhões de indivíduos em território mundial. As condições em relação a saúde mental é de grande complexidade, pois é representada por fenômenos graves que envolvem as atividades sociais. Podem ter alucinações, condutas ou expressões confusas, apatia e retração de sociabilidade. Tende a manifestar níveis de maneira elevada de cortisol e transformações no mecanismo serotoninérgico (Chaves et al., 2020). "O cortisol é um dos hormônios mais abundantes no corpo e seus níveis aumentam na presença de estresse físico e/ou psicológico. Um nível elevado de cortisol pode ser um gatilho para reações psicofisiológicas que resultam na hiperfunção do sistema nervoso simpático e do sistema 
endócrino, especificamente das glândulas adrenais" (Neto et al., 2019). Indivíduos com SZC tendem a desenvolver a depressão, desse modo, inibidores de recaptação da serotonina opera como um medicamento (Tuleski, 2019).

\subsubsection{Alzheimer e a vitamina D}

As doenças neurodegenerativas são enfermidades descritas pela destruição de alguns neurônios de forma irreversível, o que acarreta em danos progressivos de certas funções do sistema nervoso. A doença de Alzheimer (DA) por exemplo, que na contemporaneidade, retrata a forma mais frequente de demência na terceira idade e verifica-se na DA que as capacidades cognitivas dos indivíduos ficam comprometidas. As informações neuropatológicas mais pertinentes em vítimas de DA são o aparecimento de atrofia cortical difusa, degeneração neurovascular, males neuronais e sinápticas abarcando diferentes sistemas de neurotransmissão, presença de placas senis extracelulares concebidas de agregados filamentosos da proteína $\beta$-amilóide (A $\beta)$ e massas neurofibrilares intracelulares, constituídas sobretudo pela proteína tau. Têm-se sucedido inúmeros estudos de antidepressivos no cenário da DA. "Por exemplo, um estudo a respeito de um inibidor seletivo da recaptação de serotonina (SSRI - do inglês, Selective Serotonin Re-uptake Inhibitor), o cloridrato de sertralina, indicou resultados positivos, em contraste com outros estudos a respeito do mesmo fármaco, e ainda outros dois antidepressivos: fluoxetina e citalopram" (Falco et al., 2016).

De maneira enfatizadora, pesquisas realizadas demonstraram uma preponderância maior de escassez da vitamina D em enfermos com DA. A vitamina D trabalha suas atividades mediante ao receptor da vitamina D (VDR), presente em abundantes tecidos, incluindo no sistema nervoso. Em determinadas análises constatou-se que a falta da vitamina está ligada ao déficit cognitivo. O receptor da vitamina D compartilha-se com o receptor retinóide $\mathrm{X}(\mathrm{RXR})$ com finalidade do nutriente atuar nos seus procedimentos. A intensificação do RXR é apto para incentivar os meios fisiológicos habituais por via das quais a APP (proteína beta-amilóide) é anulada do cérebro, expondo a cooperação de um elemento gênico relacionado com a fisiologia da vitamina D no fundamento da DA. Dessa forma, agonistas do RXR têm potencial na intervenção da DA e de suas etapas premissas (Câmera; 2019). Essa vitamina é um pró-hormônio, isto significa, que é biologicamente inativa, fazendo-se obrigatório a ocorrência de ações da radiação eletromagnética sobre o 7-deidrocolesterol para seu estímulo. Duas hidroxilações fazem-se necessárias para o desenvolvimento do composto ativo: primeiramente, dá-se no fígado, produzindo a 25hidroxivitamina D (25-OHD3), nomeada calcidiol. Segundamente, a hidroxilação que acontece nos rins e configura-se seus dois metabólitos essenciais , a 1 $\alpha, 25$-dihidroxivitamina D [1 $\alpha, 25-(\mathrm{OH}) 2 \mathrm{D} 3]$, dita popularmente como calcitriol, e o 24R,25dihidroxivitamina D3 [24R,25(OH)2D3], também afamado por 24-hidroxicalcidiol3. O rim é uma região indispensável na regulação endócrina da vitamina $\mathrm{D}$, que sucede por meio da administração sistemática da ação da enzima 1-hidroxilase. A produtividade do calcitriol é articulada de acordo com as concentrações de cálcio e ulteriores primordialidades endócrinas do organismo (Cardoso et al., 2020). O quadro 1 apresenta os sintomas recorrentes em cada doença e transtorno mental como tratamento o neurotransmissor serotonérgico. 
Quadro 1 - Resumo das patologias, questões nutricionais e seus envolvimentos com a serotonina.

\begin{tabular}{|c|c|c|c|}
\hline Patologia & Sintomatologia & Aspectos nutricionais & Serotonina \\
\hline Depressão & $\begin{array}{l}\text { Infelicidade ou irritabilidade, falta de } \\
\text { prazer e energia, ausência de auto } \\
\text { estima, frustação, pessimismo, } \\
\text { arrependimento, diminuição de } \\
\text { concentração, morte e perspectivas em } \\
\text { relação ao suicídio. }\end{array}$ & $\begin{array}{l}\text { A deficiência da vitamina } \\
\text { B12 provoca a depressão. }\end{array}$ & $\begin{array}{c}\text { Atua como regulador da atividade } \\
\text { psicomotora, apetite, sono e } \\
\text { humor. }\end{array}$ \\
\hline TDAH & $\begin{array}{c}\text { Desconcentração, ansiedade, atitudes } \\
\text { impulsivas e exagero de ações } \\
\text { motoras. }\end{array}$ & $\begin{array}{l}\text { A falta dos minerais zinco e } \\
\text { ferro se faz presente em } \\
\text { conjunto com a desnutrição. }\end{array}$ & $\begin{array}{l}\text { Encarrega-se pela ativação nas } \\
\text { regiões do cérebro do lobo frontal } \\
\text { que ajuda na concentração e } \\
\text { atenção com outros } \\
\text { neurotransmissores. }\end{array}$ \\
\hline TEA & Déficits sociais e comportamentais. & $\begin{array}{l}\text { Vitamina B9 possui } \\
\text { relevância para o progresso } \\
\text { do tubo neural. }\end{array}$ & $\begin{array}{c}\text { Age como um coadjutor para os } \\
\text { comportamentos recorrentes e na } \\
\text { ansiedade. }\end{array}$ \\
\hline SZC & $\begin{array}{c}\text { Alucinações, condutas ou expressões } \\
\text { confusas, apatia e retração de } \\
\text { sociabilidade. }\end{array}$ & Níveis elevados de cortisol. & Serve como uma medicação. \\
\hline DA & $\begin{array}{l}\text { Atrofia cortical difusa, degeneração } \\
\text { neurovascular, distúrbios neuronais e } \\
\text { sinápticos, presença de células } \\
\text { formadas por agregados filamentosos } \\
\text { de } \beta \text {-amilóide (A } \beta \text { ) e aglomerados de } \\
\text { neurofibrilas intracelulares (compostos } \\
\text { principalmente de proteína tau). }\end{array}$ & Escassez da vitamina D. & $\begin{array}{l}\text { Atua como um inibidor } \\
\text { antidepressivo. }\end{array}$ \\
\hline
\end{tabular}

Fonte: Elaborado pelos autores.

Os dados adquiridos no estudo sistemático revelam que a serotonina é capaz de colaborar como uma intervenção benéfica para a depressão, transtorno do déficit de atenção e hiperatividade, autismo, esquizofrenia e Alzheimer. Assim, desempenha uma relevância para amenizar os sintomas de cada doença e transtornos escolhidos para análise do presente estudo. A serotonina (5-hidroxitriptamina, ou 5-HT) está diretamente conectada ao nosso bem-estar e júbilo, pois esse neurotransmissor concerne como uma explosão de euforia e quando há uma variação na elaboração ou absorção no corpo já é um meio considerável para intensificar ou decair a percepção de alegria ou de infelicidade. Portanto, no momento que a 5-HT reduz, ocorre mais chances do desenvolvimento maléfico se proliferar em respeito da sanidade mental, ou seja, doenças como a depressão e transtornos mentais podem surgir e devido a isso as emoções sentidas do sujeito passam a ser negativas e dificultosas. Nessa ocasião, a serotonina advém como uma ajuda para oferecer o equilíbrio da saúde mental.

É importante destacar que os transtornos mentais podem ser tidos como campos de observação e exploração interdisciplinar envolvendo as áreas da saúde, em especial a psicologia. As doenças psíquicas e os transtornos contemplam alterações de pensamentos, atitudes e emoções. Em função disso, as questões do desenvolvimento de uma saúde mental inadequada pode-se relacionar a situações vividas desde o sujeito em formação, por exemplo, uma renegação por parte do pai ou da mãe é capaz de possuir um potencial de uma predisposição psicológica mal formada para o filho.

Em conformidade a área explícita, os transtornos mentais conseguem se desenvolver também por meio de uma combinação de fatores biológicos, da mesma forma, os quadros de estresse intensos, características da personalidade (agressividade) e a parte do contexto social em que está se vivendo pode intensificar de maneira negativa a sanidade mental do indivíduo. Ademais, mesmo que uma pessoa tenha sua particularidade genética e sua parte de personalidade que a torna vulnerável aos transtornos, precisa-se de um gatilho em âmbito social e psicológico para propagar os sintomas e sinais.

Na psicologia existe uma teoria, denominada teoria do "big Five", essa hipótese corresponde a um modelo de verificação de uma pessoa que origina as características de sua personalidade. É constituída por neuroticismo, extroversão, 
abertura à experiência, socialização e realização. O neuroticismo refere-se a instabilidade emocional, a extroversão condiz a sensação do bem-estar, a abertura à experiência reflete a criatividade, a socialização representa a interação social e o modo de como essa comunicação é realizada e por último, a realização, que se relaciona a concentração.

As funções das cinco fases em sujeitos com doenças psíquicas e transtornos mentais, respectivamente, pode-se ressaltar que um indivíduo com maior neuroticismo, podem ser extremamente ansiosas, já na extroversão podemos dizer que no caso dessas pessoas, seriam introvertidas, pois não tem a exuberância social e necessitam de um certo estímulo para mudar seu humor, a abertura à experiência, pode-se possuir um grau baixo e dar preferência ao tradicional sem estimular sua criatividade, na socialização a interação humana é retraída e diz respeito a realização, a concentração é extremamente baixa. A personalidade é a soma das características emocionais de uma pessoa, ou seja, é uma ampla gama de fatores, envolvendo não apenas o caráter de uma pessoa, mas também uma série de reações, características e definições de comportamento. Portanto, no contexto da saúde mental do ser, pode-se mencionar que a personalidade baseada na psicologia consegue interferir em possíveis transtornos mentais.

Em referência a nutrição com a serotonina pode-se emergir que uma refeição traz consigo uma série de fatores sensoriais, comportamentais e emocionais. Isto é, costuma-se, em determinada maioria, pessoas ficarem felizes ao praticar o ato de comer, principalmente com certos alimentos ricos no aminoácido triptofano, porque o próprio a partir da alimentação já facilita a sintetização da serotonina que é intitulada como o "hormônio do prazer" que por consequência está ligado ao tratamento e prevenção da depressão, dos transtornos mentais e sintomatologias comuns como ansiedade, insônia e perda do apetite. De acordo com Pinheiro et al. ( 2017) não é possível obter o triptofano no organismo, pois não somos capazes de produzi-lo, com isso, só podemos obtê-lo através dos alimentos. Diante disso, com base nessa alegação pode-se observar que uma alimentação inadequada em ênfase a alimentos com baixo teor do triptofano, que é único precursor da serotonina, faz a 5HT diminuir provocando uma baixa qualidade de vida.

É primordial ressaltar que as variações no sistema serotoninérgico podem causar o mau funcionamento do trato gastrointestinal. O sistema gastrointestinal produz 95\% da serotonina pelas células enteroendócrinas ou enterocromafins nas vísceras, especificamente no intestino e também são produzidas pelos neurônios da 5-HT do sistema nervoso entérico. As funções nervosas do trato gastrointestinal são controladas pelo SNE (sistema nervoso intrínseco) e uma rede nervosa extrínseca composta pelos circuitos parassimpático e simpático que interagem com o sistema nervoso entérico.

O circuito parassimpático é distribuído pelos nervos vago e pélvico, cujo os longos axônios manifestam-se dos corpos celulares da área sacral e cervical da medula espinal que por sua vez, alcançam aos diferentes órgãos do trato gastrointestinal, os quais realizam sinapse com as células do Sistema nervoso entérico. O percurso aferente programa para a medula espinal e cérebro os incentivos sensoriais por meio da intercomunicação das células nervosas com receptores encontrados nos tecidos do intestino delgado. Já os neurônios eferentes vagais proporcionam uma inervação por fibras profusas que surgem no plexo mioentérico do estômago e esôfago. A sua inervação no intestino delgado não é tão extensa.

Os neurônios aferentes e eferentes vagais, executam um papel com uma certa relevância no trato gastrointestinal superior, cujos auxiliam a organizar as reações motoras e secretoras da deglutição dos alimentos. Ainda mais, a serotonina se exibe como um neurotransmissor necessário quando se envolve na interatividade entre o SNE e o SNC, além de ser um dos neurotransmissores-chave para o trato gastrointestinal.

A pesquisa feita pode contribuir de forma significativa, visto que, propõe uma ligação coerente em relação à depressão e transtornos mais frequentes, seguindo a lógica nutricional com o sistema nervoso, devido o neurotransmissor estudado, serotonina, atuar no cérebro e estabelecer a comunicação entre as células nervosas que são responsáveis por sistematizar as atividades do organismo e uma vez que, a alimentação é ingerida, implicará no funcionamento da complexidade que é nosso corpo humano, principalmente a parte cerebral. Além disso, consiste em apresentar dados para a 
população de modo geral, seja na faixa etária infantil até a idosa de modo que a serotonina e a alimentação resultam como melhor intercessão para uma qualidade de vida mais saudável. Em suma, têm-se informações relevantes para a ciência abrir novas perspectivas ao sistema serotoninérgico para com a nutrição.

\section{Conclusão}

Em vista dos argumentos apresentados e analisados obteve-se uma ampliação sobre o sistema serotonérgico e sua capacidade de melhora em respectivos fatores em relação a saúde mental, de modo que a serotonina pode influenciar beneficamente no tratamento em conjunto com a alimentação adequada para cada doença, como a depressão e transtornos, como a TDAH, TEA, SCZ E DA, uma vez que, deficiências nutricionais acontecem no decurso das respectivas patologias expostas. A serotonina atua como um regulador do sono e auxilia na regulação da temperatura corporal, no apetite, humor, na atividade motora e na cognição. Esse neurotransmissor é sintetizado no cérebro a partir do principal aminoácido triptofano (TRP) e como o corpo não consegue sintetizar o TRP, ele só pode ser conquistado por meio da alimentação. Con soante ao presente estudo, a escassez das vitaminas B2, B6, B9, B12 e D em conjunto com a ausência dos minerais zinco e ferro, acarreta nas funções mentais dos indivíduos. Logo, notabiliza-se a relação da serotonina com a dieta como um coadjutor para o tratamento de pessoas com disfunção da atividade cerebral. Por fim, faz-se necessário mais investigações acerca do tema abordado para outras finalidades, além das questões encontradas e relacionadas ao neurotransmissor serotonina. Para estudos futuros, será importante realizar mais pesquisas sobre os alimentos que ativam o triptofano devido que a partir dele ocorre a produção da serotonina no organismo e também será significativo efetuar a continuidade da relação do neurotransmissor serotonérgico com outros transtornos e doenças mentais a fim de oferecer ênfase a sua participação e importância na saúde cerebral.

\section{Referências}

Aquino, R. C., \& Philippi, S. T. (2017). Nutrição clínica: estudos de casos comentados. (2a ed.), Manole.

Bonan, C., Texeira, L. A. \& Nakano, A. R. (2017). Absorção e metabolização dos hormônios sexuais e sua transformação em tecnologias contraceptivas: percursos do pensamento médico no Brasil. Ciência \& Saúde Coletiva, 22(1), 107-16. https://doi.org/10.1590/1413-81232017221.26532016

Carelle, A. C., \& Cândido, C. C. (2014). Nutrição e Farmacologia. (2a ed.), Érica.

Câmera, A. B. (2019). Receptores neurais e a doença de Alzheimer: uma revisão sistemática da literatura sobre as famílias de receptores mais associados a doença, suas funções e áreas de expressão. Jornal Brasileiro de Psiquiatria [online], 68(3), 161-176. https://doi.org/10.1590/0047-2085000000242

Carvalho, M. S., Mas, C. D., Nunes, D. F. S., Yonamine, C. M., \& Hayashi, M. A. F. (2017). Metabolismo do triptofano em transtornos mentais:Um enfoque na esquizofrenia. Vitalle. Revista de Ciências da Saúde, 29(2), 44-56. https://doi.org/10.14295/vittalle.v29i2.6550

Cardoso, F. L. E., Santos, L. C. M., Tenório, A. P. O., Lopes, M. R., \& Barbosa, R. H. A. (2020). Suplementação de vitamina D e seus análogos para tratamento de disfunção endotelial e doenças cardiovasculares. Jornal Vascular Brasileiro [online], 19. https://doi.org/10.1590/1677-5449.190150

Cotrim, J. R., Lemos, A. G., Júnior, J. E. N., \& Barela, J. A. (2012). Desenvolvimento de habilidades motoras fundamentais em crianças com diferentes contextos escolares. Journal of Physical Education, 22(4), 523-533. https://doi.org/10.4025/reveducfis.v22i4.12575

Chaves, L. G. S., Gama, D. R. N., Castro, J. B. P., Oliveira, K. R. S. G., \& Vale, R. G. S. (2020). Cortisol and serotonin levels in schizophrenic inpatients undergoing aerobic training. Revista Brasileira de Medicina do Esporte, 26(4). https://doi.org/10.1590/1517-869220202604224027

Fábregas, B. C., Vitorino, F. D., \& Texeira, A. L. (2011). Deficiência de vitamina B12 e transtorno depressivo refratário. J Bras Psiquiatr, 60(2), 141-143. https://doi.org/10.1590/S0047-20852011000200010

Falco, A., Cukierman, D. S., Davis, R. A. H., \& Rey, N. A. (2016). Doença de Alzheimer:Hipóteses etiológicas e perspectivas de tratamento. Química nova [onilne], 39(1), 63-80. https://doi.org/10.5935/0100-4042.20150152

Ferreira, C. V., Góis, R. S., Gomes, L. P., Britto, A., Afrânio, B., \& Dantas, E. H. M. (2017). Nascidos para correr: A importância do exercício para a saúde do cérebro. Revista Brasileira de Medicina do Esporte 23(6), 495-503. https://doi.org/10.1590/1517-869220172306175209

Feijó, F. M., Bertoluci, M. C., \& Reis, C. (2011). Serotonina e controle hipotalâmico da fome: uma revisão. Revista da Associação Médica Brasileira [onilne], 57(1),74-77. https://doi.org/10.1590/S0104-42302011000100020 
Flora, R. P. D., Dionello, N. J. L., Benitez, L., Germano, J. M., Gotuzzo, A. G., \& Freitas, S. (2017). Expressão gênica de IGF-I e GHR no fígado e no músculo do peito de codornas de corte suplementadas com diferentes níveis de metionina em duas gerações sucessivas. Arquivo Brasileiro de Medicina Veterinária e Zootecnia [onilne], 69(1), 205-213. https://doi.org/10.1590/1678-4162-9143

Galvão, T. F., \& Pereira, M. G. (2014). Revisões Sistemática para a literatura: passos para a sua elaboração. Revista Epidemiologia e Serviços de Saúde, 23(1), 183-184. http://dx.doi.org/10.5123/S1679-49742014000100018

Garcia, L. R. S., Silva, J. D. M., Silva, C. S. S., Rocha, P. J. S., \& Garcia, L. C. S. (2017). Aspectos nutricionais no transtorno de atenção/hiperatividade em crianças. Carp Diem: Revista Cultural e Científica Unifacex, 15(1), 11-28. https://periodicos.unifacex.com.br/Revista/article/view/855

Guyton, A. C., \& Hall, J. E. (2017). Guyton e Hall:Fundamentos da fisiologia. (13a ed.), Elsevier.

Hall, J. E. (2021). Tratado de fisiologia médica. (13a ed.), Guanabara Koogan Ltda.

Maia, C. S., Menezes, K. M. C., Tenorio, F. C. A. M., Júnior, J. R. A. Q., \& Maciel, G. E. S. (2019). Transtorno do espectro autista e a suplementação por ácido fólico antes e durante a gestação. Jornal Brasileiro de Psiquiatria [onilne],68(4), 231-243. https://doi.org/10.1590/0047-2085000000251

Machado, I. E., Malta, D. C., Bacal, N. S., \& Rosenfeld, L. G. M. (2019). Prevalência de anemia em adultos e idosos brasileiros. Revista Bras de Epidemiologia, 22(02), e190008. https://doi.org/10.1590/1980-549720190008.supl.2

Martins, J. T., Silva, M. C., \& Streck, E. L. (2017). Efeitos da vitamina B12 no cérebro. Revista Nova Saúde, 6(1). http://dx.doi.org/10.18616/is.v6i1.3058

Neto, L. M. L., Vasconcelos, F. M. N., Silva, J. E., Pinto, T. C. C., Sougey, E. B., \& Ximenes, R. C. C. (2019). Diferenças nas concentrações de cortisol em adolescentes com transtornos alimentares: uma análise sistemática. Jornal Pediatria [onilne], 95(1), 18-26. https://doi.org/10.1016/j.jped.2018.02.007

Neto, S. G. B., Brunoni, D., \& Cysneiros, R. M. (2019). Abordagem psicofarmacológica no transtorno do espectro autista: uma revisão narrativa. Cadernos de Pós-Graduação em Distúrbios do Desenvolcimento, 19(2), 38-60. http://dx.doi.org/10.5935/cadernosdisturbios.v19n2p38-60

Pinheiro, I. L., Santana, B. J. R. C., Galindo, L. C. M., Castro, R. M., \& Sousa, S. L. (2017). Perinatal serotonergic activity: A decisive factor in the control of food intake. Revista Nutrição [onilne], 30(4), 535-544. https://doi.org/10.1590/1678-98652017000400012

Santos, E. C., Brito, A., \& Pereira, I. R. O. (2016). Deficiência da vitamina B12: um fator que induz a depressão?. Cadernos de Pós-Graduação em Distúrbios do Desenvolvimento, 16(2), 33-46. http://dx.doi.org/10.5935/1809-4139.20160005

Sauressig, C., Silva, V. L., Antunes, L. C., \& Dall'alba, V. (2016). Níveis de Zinco sérico em pacientes internados com depressão. Jornal Brasileiro de Psiquiatria [onilne], 65(3), 239-244. https://doi.org/10.1590/0047-2085000000130

Siqueira, K. B., Binoti, M. L., Nunes, R. M., Borges, C. A. V., Pilati, A. F., Marcelino, G. W., Gama, M. A. S., \& Silva, P. H. F. (2020). Custo benefício dos nutrientes dos alimentos consumidos no Brasil. Ciência e Saúde Coletiva [onilne], 25(3), 1129-1135. https://doi.org/10.1590/1413-81232020253.11972018

Sthal, S. M. (2019). Psicofarmacologia: bases neurocientíficas e aplicações prática. (4a ed.), Guanabara Koogan

Tuleski, S. C. (2019). A unidade do Psiquismo Humano para Vigotski e a Desagregação desta na Esquizofrenia. Psicologia: Teoria e pesquisa [onilne], 35, e35424. https://doi.org/10.1590/0102.3772e35424

Vanputte, C., Regan, J., \& Russo, A. (2016). Anatomia e fisiologia. (10a ed.), AMGH. 